\title{
A new species of Heterospio (Annelida, Longosomatidae) from the Indian Ocean
}

\author{
Julio PARAPAR ${ }^{1, *}$, Tejal VIJAPURE ${ }^{2}$, Juan MOREIRA ${ }^{3}$ \& Soniya SUKUMARAN ${ }^{4}$ \\ ${ }^{1}$ Departamento de Bioloxía Animal, Bioloxía Vexetal e Ecoloxía, Facultade de Ciencias, Universidade \\ da Coruña, Rúa da Fraga 10, E-15008 A Coruña, Spain. \\ ${ }^{2,4}$ CSIR-National Institute of Oceanography (NIO), Regional Centre, Mumbai, India. \\ ${ }^{3}$ Departamento de Biología (Zoología), Facultad de Ciencias, Universidad Autónoma de Madrid, \\ Cantoblanco, E-28049 Madrid, Spain. \\ *Corresponding author: jparapar@udc.es \\ ${ }^{2}$ Email: tejaalvijapure@gmail.com \\ ${ }^{3}$ Email: juan.moreira@uam.es \\ ${ }^{4}$ Email: soniya@nio.org

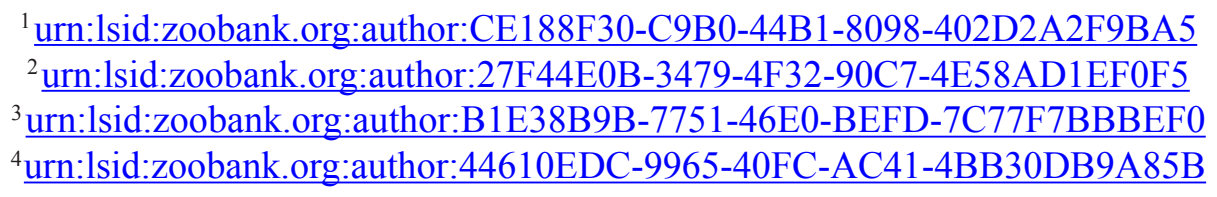

\begin{abstract}
Knowledge about the taxonomy and distribution of the monogeneric polychaete family Longosomatidae Hartman, 1944 is limited in all parts of the world. A new species of the genus Heterospio Ehlers, 1874 (Annelida, Longosomatidae) is described from the Indian Ocean. Heterospio indica sp. nov. is mainly characterised by the conspicuous flattening of the distal half of capillary chaetae located in anterior elongated segments. Several body characters of high taxonomic relevance in the genus are examined under the SEM and discussed. The 18S SSU rDNA and COI genes were sequenced and represent the first sequencing of a species of Heterospio, and the sequences have been deposited in GenBank.
\end{abstract}

Keywords. Polychaeta, Heterospio indica new species, taxonomy, SEM, DNA barcodes.

Parapar J., Vijapure T., Moreira J. \& Sukumaran S. 2016. A new species of Heterospio (Annelida, Longosomatidae) from the Indian Ocean. European Journal of Taxonomy 220: 1-17. http://dx.doi.org/10.5852/ejt.2016.220

\section{Introduction}

The family Longosomatidae Hartman, 1944 comprises a single genus, Heterospio Ehlers, 1874, that includes eight described species, namely $H$. longissima Ehlers, 1874, H. longissima Ehlers sensu Hartman 1965, H. catalinensis Hartman, 1944, H. mediterranea Laubier, Picard \& Ramos, 1973, H. reducta Laubier, Picard \& Ramos, 1973, H. peruana Borowski, 1994, H. sinica Wu \& Chen, 1996 and H. angolana Bochert \& Zettler, 2009 (see Parapar et al. 2014), as well as two described, but still 
Table 1. Details of sampling locations off the west coast of India where specimens of Heterospio indica sp. nov. were found.

\begin{tabular}{|c|c|c|c|c|c|}
\hline Area & Study period & $\begin{array}{c}\text { Station code } \\
\text { (sampling date) }\end{array}$ & Location & $\begin{array}{l}\text { Depth } \\
\text { (m) }\end{array}$ & Sediment \\
\hline \multirow{4}{*}{ Malvan } & Premonsoon & M2 (2 Apr. 2013) & $16^{\circ} 02^{\prime} 41.7^{\prime \prime} \mathrm{N}, 73^{\circ} 26^{\prime} 16.8^{\prime \prime} \mathrm{E}$ & 15 & Clayey silt \\
\hline & Postmonsoon & M4 (29 Jan. 2014) & \multirow{2}{*}{$16^{\circ} 01^{\prime} 37.1^{\prime \prime} \mathrm{N}, 73^{\circ} 25^{\prime} 29.7^{\prime \prime} \mathrm{E}$} & \multirow{2}{*}{20} & \multirow{2}{*}{ Clayey silt } \\
\hline & Monsoon & M4 (22 Sep. 2014) & & & \\
\hline & Premonsoon & M3 (12 Mar. 2015) & $16^{\circ} 02^{\prime} 23.9^{\prime \prime} \mathrm{N}, 73^{\circ} 26^{\prime} 39.4^{\prime \prime} \mathrm{E}$ & 15 & Clayey silt \\
\hline \multirow[t]{5}{*}{ Ratnagiri } & \multirow[t]{3}{*}{ Premonsoon } & R1 (7 Apr. 2013) & $17^{\circ} 00^{\prime} 27.7^{\prime \prime} \mathrm{N}, 73^{\circ} 16^{\prime} 30.0^{\prime \prime} \mathrm{E}$ & 8 & Silty sand \\
\hline & & R3 (8 Apr. 2013) & $17^{\circ} 00^{\prime} 14.5^{\prime \prime} \mathrm{N}, 73^{\circ} 15^{\prime} 03.0^{\prime \prime} \mathrm{E}$ & 16 & Sandy silt \\
\hline & & R4 (8 Apr. 2013) & $17^{\circ} 00^{\prime} 09.1^{\prime \prime} \mathrm{N}, 73^{\circ} 13^{\prime} 50.6^{\prime \prime} \mathrm{E}$ & 20 & Clayey silt \\
\hline & Postmonsoon & R4 (3 Feb. 2014) & \multirow{2}{*}{$17^{\circ} 00^{\prime} 09.1^{\prime \prime} \mathrm{N}, 73^{\circ} 13^{\prime} 50.6^{\prime \prime} \mathrm{E}$} & \multirow{2}{*}{20} & \multirow{2}{*}{ Clayey silt } \\
\hline & Monsoon & R4 (27 Sep. 2014) & & & \\
\hline \multirow[t]{2}{*}{ Mumbai } & Premonsoon & MY2 (15 Mar. 2013) & $18^{\circ} 51^{\prime} 19.0^{\prime \prime} \mathrm{N}, 72^{\circ} 50^{\prime} 37.6^{\prime \prime} \mathrm{E}$ & 10 & Clayey silt \\
\hline & Monsoon & MY4 (24 Sep. 2014) & $18^{\circ} 49^{\prime} 36.7^{\prime \prime} \mathrm{N}, 72^{\circ} 47^{\prime} 34.1^{\prime \prime} \mathrm{E}$ & 18 & Sandy silt \\
\hline \multirow[t]{2}{*}{ Veraval } & Premonsoon & V4 (19 Mar. 2013) & $20^{\circ} 51^{\prime} 03.4^{\prime \prime} \mathrm{N}, 70^{\circ} 22^{\prime} 36.3^{\prime \prime} \mathrm{E}$ & 22 & Sandy silt \\
\hline & Monsoon & V2 (21 Sep. 2014) & $20^{\circ} 53^{\prime} 59.9^{\prime \prime} \mathrm{N}, 70^{\circ} 22^{\prime} 28.8^{\prime \prime} \mathrm{E}$ & 2.5 & Sandy silt \\
\hline
\end{tabular}

unnamed species (Heterospio sp. A sensu Uebelacker 1984; Heterospio sp. 1 sensu Borowski 1994) and one undescribed (Knox 1960). Members of this family are mostly reported from muddy sediments on continental shelfs and slopes worldwide (Wilson 2000). According to Rouse (2001) their elongated body is characterized by an anterior region composed by 7-9 short segments and provided with 3-8 pairs of branchial filaments, a post-branchial region composed of elongate segments and a bulbous posterior region with terminal pygidium. The length of the first elongated segments, number of pairs of branchiae and chaetal types are the main taxonomic characters used to differentiate between species (e.g., Wu \& Chen 1966; Laubier et al. 1973; Wilson 2000; Bochert \& Zettler 2009; Parapar et al. 2014).

The type species of the genus, Heterospio longissima Ehlers, 1874, was described from specimens collected off the coast of Ireland, NE Atlantic Ocean (Ehlers 1874). This species was subsequently reported in numerous localities in the same ocean and in the Sea of Japan (see fig. 8 in Parapar et al. 2014). In the Indian Ocean the only records of the genus correspond to one specimen of H. longissima off the coast of Sudan, Red Sea (Rosenfeldt 1989; Türkay 1996; Wehe \& Fiege 2002), and two specimens off the Indian and Pakistani coast of the Arabian Sea (Hartman 1974; Wehe \& Fiege 2002; Rao 2005; Kazmi \& Naushaba 2013) (Fig. 1).

During a benthic investigation in shallow waters off the west coast of India, several specimens of the genus Heterospio were collected; they belong to a new species which is described herein, both morphologically (including SEM study) and genetically (including 18S SSU rDNA and COI sequences); information about its habitat is also provided. The distribution of the genus in nearby areas of the Indian Ocean is also reviewed. 
Table 2. List of PCR and sequencing primers.

\begin{tabular}{llll}
\hline Gene & Primer & & Reference \\
\hline $18 \mathrm{~S}$ & 18SA & AYCTGGTTGATCCTGCCAGT & Medlin et al. (1988) \\
& & & Persson (pers. comm.); Norlinder et al. \\
& $584 \mathrm{R}$ & ACGCTATTGGAGCTGGAAT & $(2012)$ \\
CO1 & HCO 2198 & TAAACTTCAGGGTGACCAAAAAATCA & Folmer et al. (1994) \\
& LCO 1490 & GGTCAACAAATCATAAAGATATTGG & \\
\hline
\end{tabular}

\section{Material and methods}

This study is based on material collected by several sampling campaigns off the central west coast of India. Specimens were collected in different seasons across subtidal areas off Malvan, Ratnagiri, Mumbai and Veraval during 2013-2015 (Table 1). Samples were taken with a van Veen grab with a $0.04 \mathrm{~m}^{2}$ sampling area. Most of the specimens were fixed in 5\% formaldehyde in seawater solution, and then preserved in $70 \%$ ethanol for morphological identification. Some specimens were put directly into $96 \%$ ethanol for molecular studies. Samples were sorted at the CSIR-National Institute of Oceanography (CSIR-NIO), Regional Centre, Mumbai, India. All studied specimens were deposited in the collections of the Museo Nacional de Ciencias Naturales de Madrid, Spain (MNCN), Senckenberg Research Institute and Natural History Museum, Frankfurt (SMF) and CSIR-National Institute of Oceanography (CSIR-NIO), Regional Centre, Mumbai.

Observations, drawings and measurements of specimens were made with an Olympus BX51 compound microscope equipped with a drawing tube. Specimens were stained with methylene blue for examination of body and parapodia under the light microscope. For examination with scanning electron microscopy (SEM), specimens were dehydrated in a graded ethanol series, critical-point dried using $\mathrm{CO}_{2}$, mounted on aluminium stubs, covered with gold in a BAL-TEC SCD 004 evaporator, and examined and photographed under a JEOL JSM-6400 scanning electron microscope at the Servizos de Apoio á Investigación (SAI), University of A Coruña (UDC), Spain.

The description is based on the holotype; features of the posterior end of the body and chaetal fine structure (SEM micrographs) are from some paratypes. Intraspecific variation is also reported whenever recorded (e.g., segment size, branchiae arrangement). For the delimitation of body segments we follow Parapar et al. (2014); these authors propose that chaetae are located on the anterior border of segments and therefore the length of a segment should be considered as the distance from the chaetal bundle (or ring) to the chaetal bundle of the next chaetiger. For comparative purposes, one specimen collected by Rosenfeldt (1989) off the Sudanese coast in the Red Sea was also studied.

Molecular analysis was carried out at CSIR-NIO, Regional Centre, Mumbai. Genomic DNA was extracted with the DNeasy Blood \& Tissue Kit (Qiagen), as per manufacturer protocol. 18S SSU rDNA was amplified using primers $18 \mathrm{SA}$ and 584R resulting in 540-545 bp sequence-lengths. $687 \mathrm{bp}$ of COI was amplified with $\mathrm{HCO} 2198$ and LCO1490 primers (for primer references see Table 2). PCR mixtures for both genes contained $5 \mu \mathrm{l}$ of Qiagen PCR buffer, $1 \mu \mathrm{dNTPs}, 38.8 \mu 1 \mathrm{ddH}_{2} \mathrm{O}, 2 \mu 1$ of each forward and reverse primer $(10 \mathrm{mM}), 1 \mu 1$ template DNA and $0.2 \mu 1$ Taq polymerase, making a total volume of $50 \mu 1$. Amplifications were carried under the following thermal conditions: $94^{\circ} \mathrm{C}$ for $3.0 \mathrm{~min}, 30$ cycles of $94^{\circ} \mathrm{C}$ for $1 \mathrm{~min}, 48^{\circ} \mathrm{C}(\mathrm{COI})$ or $50^{\circ} \mathrm{C}(18 \mathrm{~S})$ for $1 \mathrm{~min}$ and $72^{\circ} \mathrm{C}$ for $2 \mathrm{mins}$. A final elongation at $72^{\circ} \mathrm{C}$ was carried out for 10 mins followed by cooling the reaction at $4^{\circ} \mathrm{C}$. Amplified products were tested on a $0.8 \%$ agarose gel. PCR products were purified with the PCR Purification kit (Qiagen) and sequenced bidirectionally by the ABi 3730XL Genetic Analyzer: 96 capillary sequencer. The final sequences have been deposited in Genbank. 


\section{Results}

Phylum Annelida Lamarck, 1809

Family Longosomatidae Hartman, 1944

Genus Heterospio Ehlers, 1874

\section{Type species}

Heterospio longissima Ehlers, 1874.

Diagnosis (modified from Borowski 1994)

Body elongated, linear, divided in three regions. Anterior region with 6-8 short chaetigers; median region with greatly elongated segments; posterior region with few short, inflated segments. Posterior part of prostomium with a pair of lateral nuchal organs. Proboscis eversible, epithelial pouch. One pair of grooved peristomial palps, easily lost, leaving scars on lateral surfaces. Anterior region with 3-8 pairs of cirriform branchiae, usually very long, one pair per segment, arising above notopodia, beginning from chaetiger 2. Anterior region with biramous parapodia provided with simple capillaries, with or without acicular spines; elongated segments with chaetae usually forming a cincture near anterior margin; chaetae simple capillaries, may be accompanied by subuluncini, aristae chaetae, and acicular spines; posteriormost inflated chaetigers provided with strong acicular hooks.

\section{Remarks}

Following Parapar et al. (2014), the terms "thorax" and "abdomen" are not used in the diagnosis due to the lack of a clear criterion about their limits. The presence of nuchal organs on the prostomium was included in the diagnosis. The range of 7-9 short anterior chaetigers provided by Borowski (1994) is modified to 6-8, following Parapar et al. (2014). Peristomial palps were qualified as "easily deciduous" because they are not reported in most descriptions. More details are provided about the number (range) and size of branchiae. The term "parapodia biramous" is used here only for anterior segments; it is also highlighted that in elongated segments there may be a change in the arrangement of chaetae, i.e., forming cinctures, although those seem not be present in H. longissima Ehlers, 1874 sensu stricto, H. reducta Laubier, Picard \& Ramos, 1973 or H. angolana Bochert \& Zettler, 2009.

Heterospio indica sp. nov.

urn:1sid:zoobank.org:act:8C7B939E-777E-44C6-80F5-1877A49539A4

Figs 1-9; Tables 1-2

Heterospio longissima - Rosenfeldt 1989: 231, fig. 7 (not Ehlers, 1874).

?Heterospio longissima - Hartman 1974: 232 (?not Ehlers, 1874).

\section{Diagnosis}

Eight anterior chaetigers short; chaetiger 9 (CH9) first elongated segment. Eight pairs of branchiae in fully developed individuals. Chaetae forming cinctures from $\mathrm{CH} 10$, provided with both thin and robust capillary chaetae arranged in two rows; both types of chaetae highly flattened in distal half; from $\mathrm{CH} 14$ robust capillary chaetae without fine distal end, subuluncini-like, thicker than on previous chaetigers. Aristate chaetae and acicular hooks not observed on elongated segments.

\section{Etymology}

The species is named after the Indian Ocean, where the specimens of the type series were collected. 


\section{Type material}

Twenty two incomplete specimens and one posterior end were collected in 13 samples along the West coast of India (Table 1; Fig. 1).

\section{Holotype}

INDIA: Malvan, postmonsoon, M4, 29 Jan. 2014, MNCN 16.01/16996.

\section{Paratypes}

INDIA: 1 spec., Malvan, premonsoon, M2, MNCN 16.01/16997; 2 spec., Ratnagiri, premonsoon, R3, NIO/MUM/4/2013/1; 3 spec., Ratnagiri, premonsoon, R4, NIO/MUM/4/2013/2; 1 spec., Mumbai, premonsoon, MY2, NIO/MUM/3/2013/3; 1 spec., Veraval, premonsoon, V4, NIO/MUM/3/2013/4; 1 posterior end, Malvan, premonsoon, M3, MNCN 16.01/16998; 3 spec., Ratnagiri, premonsoon, R1, MNCN 16.01/16999; 3 spec. on SEM stub, Ratnagiri, premonsoon, R1, MNCN 16.01/16700; 1 spec., Ratnagiri, postmonsoon, R4, SMF 24097; 1 spec., Malvan, monsoon, M4, NIO/MUM/9/2014/5; 1 spec., Ratnagiri, monsoon, R4, NIO/MUM/9/2014/6; 1 spec., Mumbai, monsoon, MY4, NIO/MUM/9/2014/7; 1 spec., Veraval, monsoon, V2, NIO/MUM/9/2014/8; 1 spec. (sequenced), Ratnagiri, postmonsoon, R4, NIO/MUM/2/2014/R-H; 1 spec. (sequenced), Malvan, postmonsoon, M4, NIO/MUM/1/2014/M-H.

\section{Type locality}

W INDIA: Malvan, 1601'37.1" N, 73²5'29.7” E, 20 m, clayey silt (Table 1).

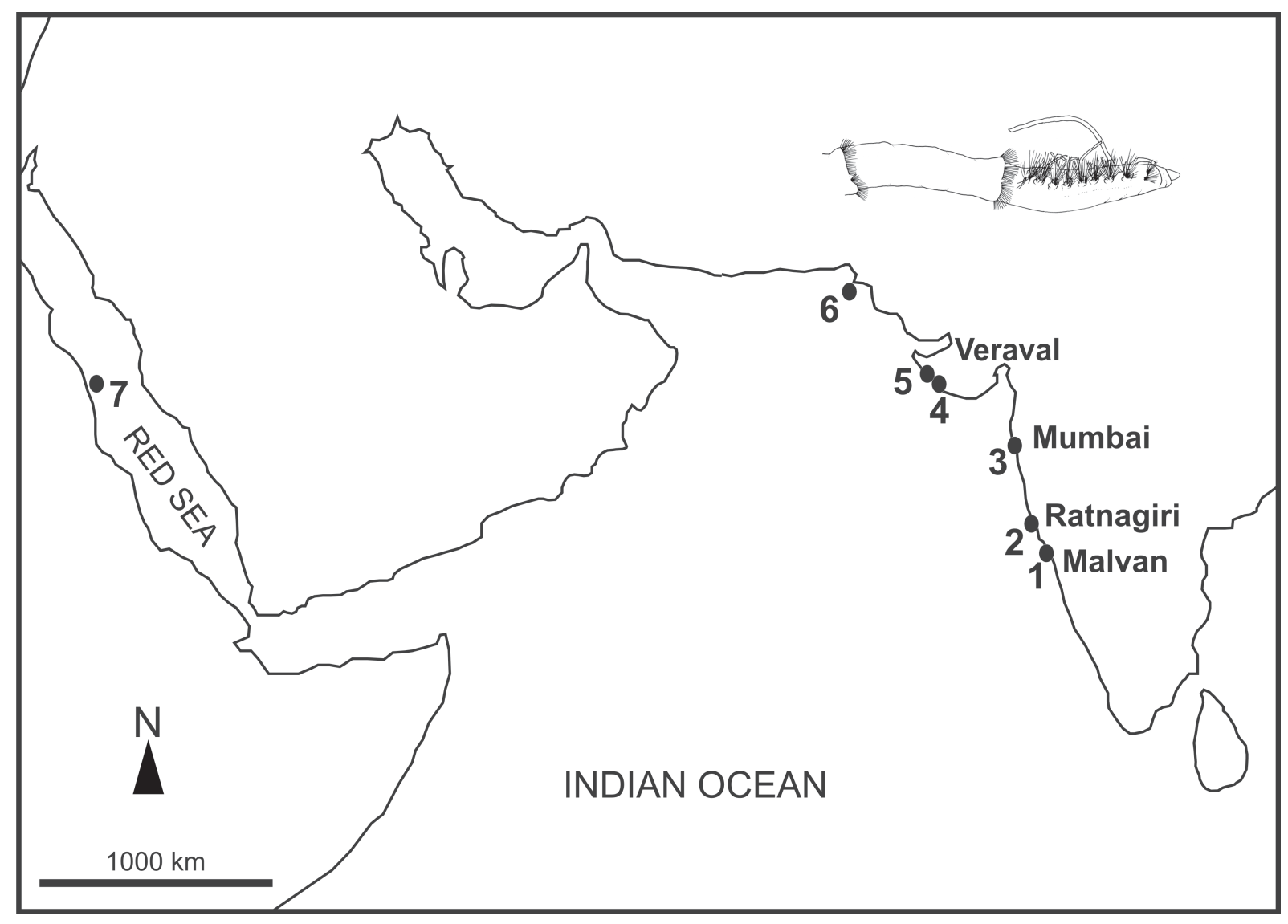

Fig. 1. Distribution of records of Heterospio around the Indian Ocean: Heterospio indica sp. nov. (present study) (1-4), H. longissima Ehlers, 1874 (data from Hartman 1974) (5-6) and H. longissima Ehlers, 1874 (data from Rosenfeldt 1989) (7). 


\section{Molecular identification}

COI and 18S nucleotide sequences of Heterospio indica sp. nov were submitted to GenBank under the accession numbers: COI-KT259053, KU221229 and 18S-KT259051, KT259052.

\section{Comparative material}

One specimen collected by Rosenfeldt (1989) off the coast of Sudan, Red Sea (SMF 3795; labelled as H. longissima).

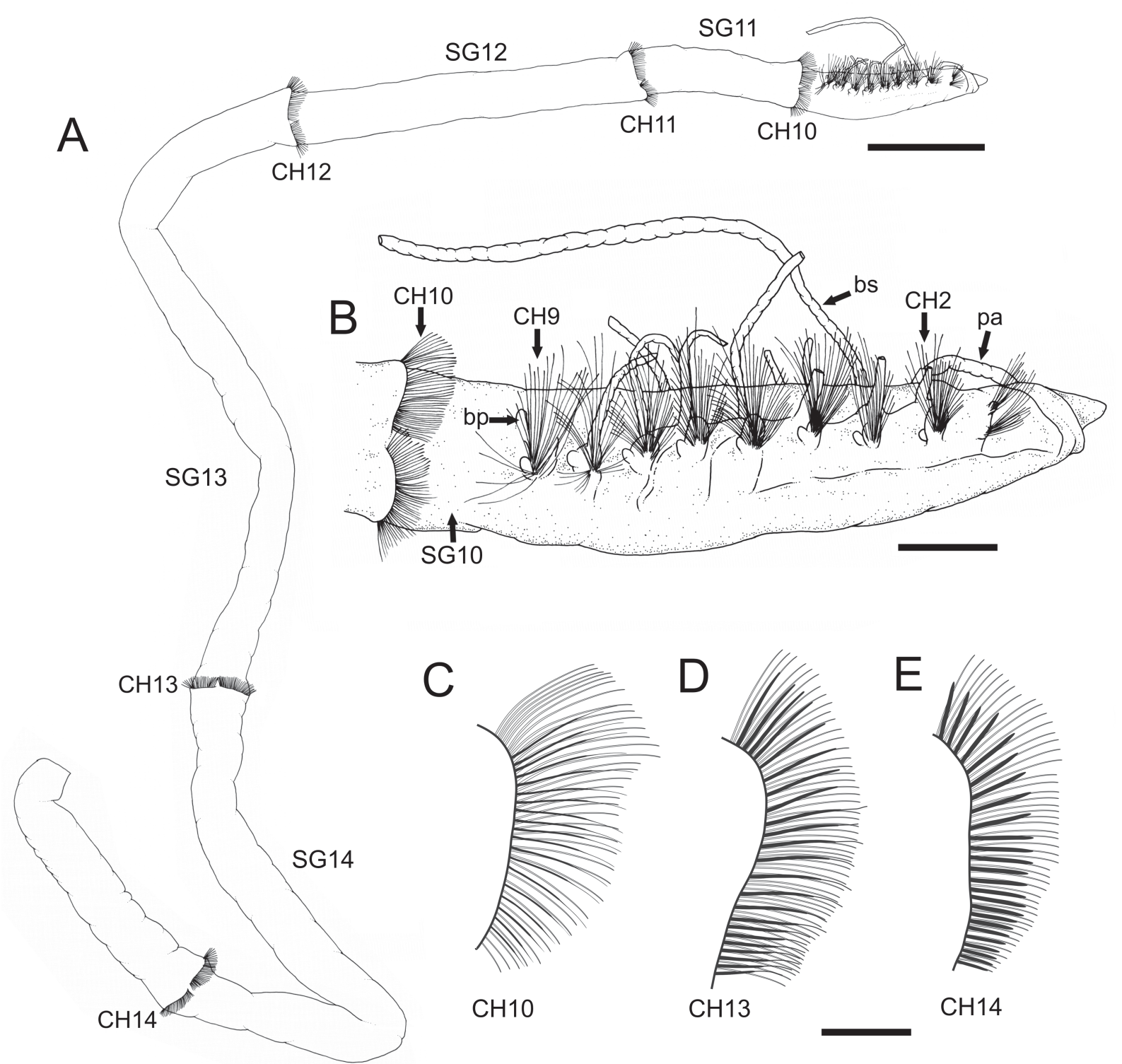

Fig. 2. Heterospio indica sp. nov., holotype (MNCN 16.01/16996). A. General view (scale bar $=2 \mathrm{~mm}$ ). B. Anterior end, lateral view (scale bar $=400 \mu \mathrm{m})$. C-E. Chaetal arrangement (scale bar $=200 \mu \mathrm{m}$ ), details. C. CH10. D. CH13. E. CH14. Abbreviations: bp = branchiophore; bs = branchiostyle; $\mathrm{CH}=$ chaetiger; $\mathrm{pa}=$ palp; $\mathrm{SG}=$ segment. 
Description of holotype (SEM images from paratypes)

Longest specimen available, incomplete, $39 \mathrm{~mm}$ long and $0.95 \mathrm{~mm}$ wide, with 14 chaetigers; body threadlike (Fig. 2A). Prostomium conical, anteriorly rounded (Figs 2B, 4A, 6C, 8C), slightly flattened dorso-ventrally. Eyes absent. Palp present on right side, reaching level of $\mathrm{CH} 2$ (Fig. 2B). Nuchal organs as deep grooves postero-lateral to prostomium, followed by deep peristomial (SG1) palp scars (Figs 4A, 6C-E). Pharynx sac-like, eversible and unarmed (Fig. 8C).

Anterior body region slightly flattened dorso-ventrally (Fig. 8B). First eight chaetigers (CH1-CH8; SG2-SG9) short, somewhat more than twice as wide as long. Chaetigers progressively longer from CH9 (SG10) onwards. CH9 first elongated chaetiger (FECH), longer than wide, about twice as long as $\mathrm{CH} 8$ (Fig. 2B) (length as distance from chaetal bundle to chaetal cincture of CH10). First chaetiger (CH1) abranchiate. Eight pairs of filiform branchiae from $\mathrm{CH} 2$ to $\mathrm{CH} 9$, dorsal to notopodia in almost all chaetigers and usually composed by short branchiophores and long branchiostyles (Figs 2B, 4B, 6B, F). From CH10 (SG11) segments strongly elongated and cylindrical in cross section (Figs 6A, 8A); length increasing in posterior segments; $\mathrm{CH} 10$ about five times longer than CH9; CH11 (SG12) about 2.5 times longer than CH10; CH12 (SG13) more than two times longer than CH11; CH13 (SG14) slightly shorter than $\mathrm{CH} 12 ; \mathrm{CH} 14$ incomplete.
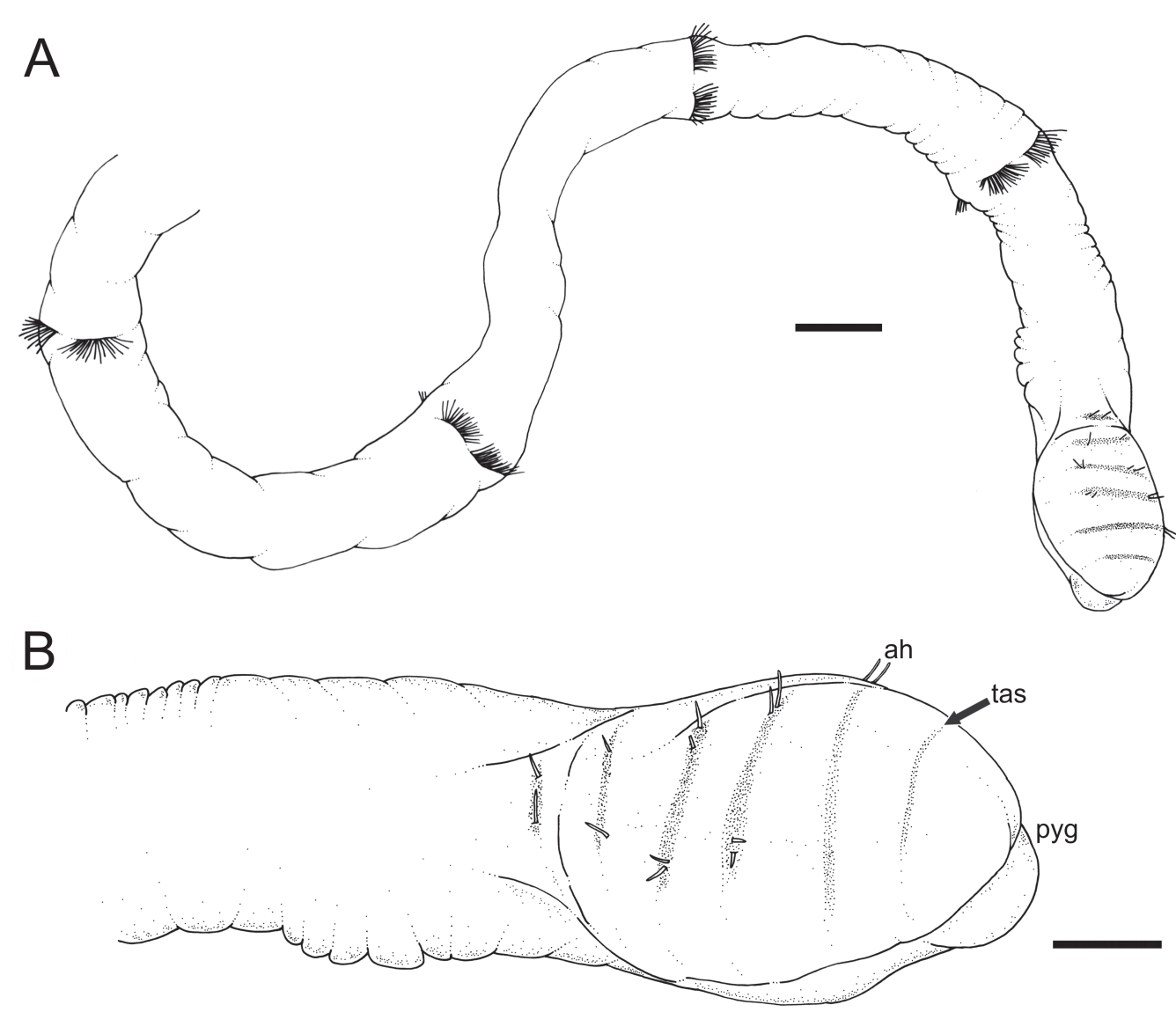

Fig. 3. Heterospio indica sp. nov., paratype (MNCN 16.01/16998). A. Posterior end (scale bar $=200$ $\mu \mathrm{m})$. B. Detail of bulbous region of posterior end (scale bar $=100 \mu \mathrm{m})$. Abbreviations: $\mathrm{ah}=$ acicular hook; pyg = pygidium; tas = terminal achaetigerous segment. 
$\mathrm{CH} 1-\mathrm{CH} 9$ provided with biramous parapodia; noto- and neuropodial chaetal fascicles well separated (Figs 2B, 5A, D, 7A, 8D, F). Parapodia from CH10 backwards as elongated ridges forming a nearly closed flange-like cincture near anterior margin of segment (Figs 2A, 5D, 8B). Chaetae of CH1-CH9 simple capillaries, in fan-shaped fascicles (Figs 2B, 4C-D). Neuropodial hooks not observed. Chaetae of $\mathrm{CH} 10$ backwards shorter than those of anterior chaetigers, arranged in two rows (Figs 2C, 5B, 7C); anterior row of robust capillary chaetae and posterior row of fine capillary chaetae (Fig. 5E-F). Both types of chaetae circular in cross section at base but quickly flattening outwards and becoming much thinner at distal end (Figs 5C, F, 7B, D, 8E). Distal ends of both types of chaetae very similar in length and width, and provided with an opening at the beginning of the terminal flattening (Figs 5C, 7B, 8E). CH12-CH13 (Fig. 2D) also with some robust capillary chaetae lacking flat distal end (i.e., subuluncinilike chaetae); $\mathrm{CH} 14$ (Fig. 2E) with all robust capillary chaetae of subuluncini-like type. No aristate chaetae or acicular hooks observed.

For a description of the posterior end, see below.

Fixed specimens creamy white in colour.
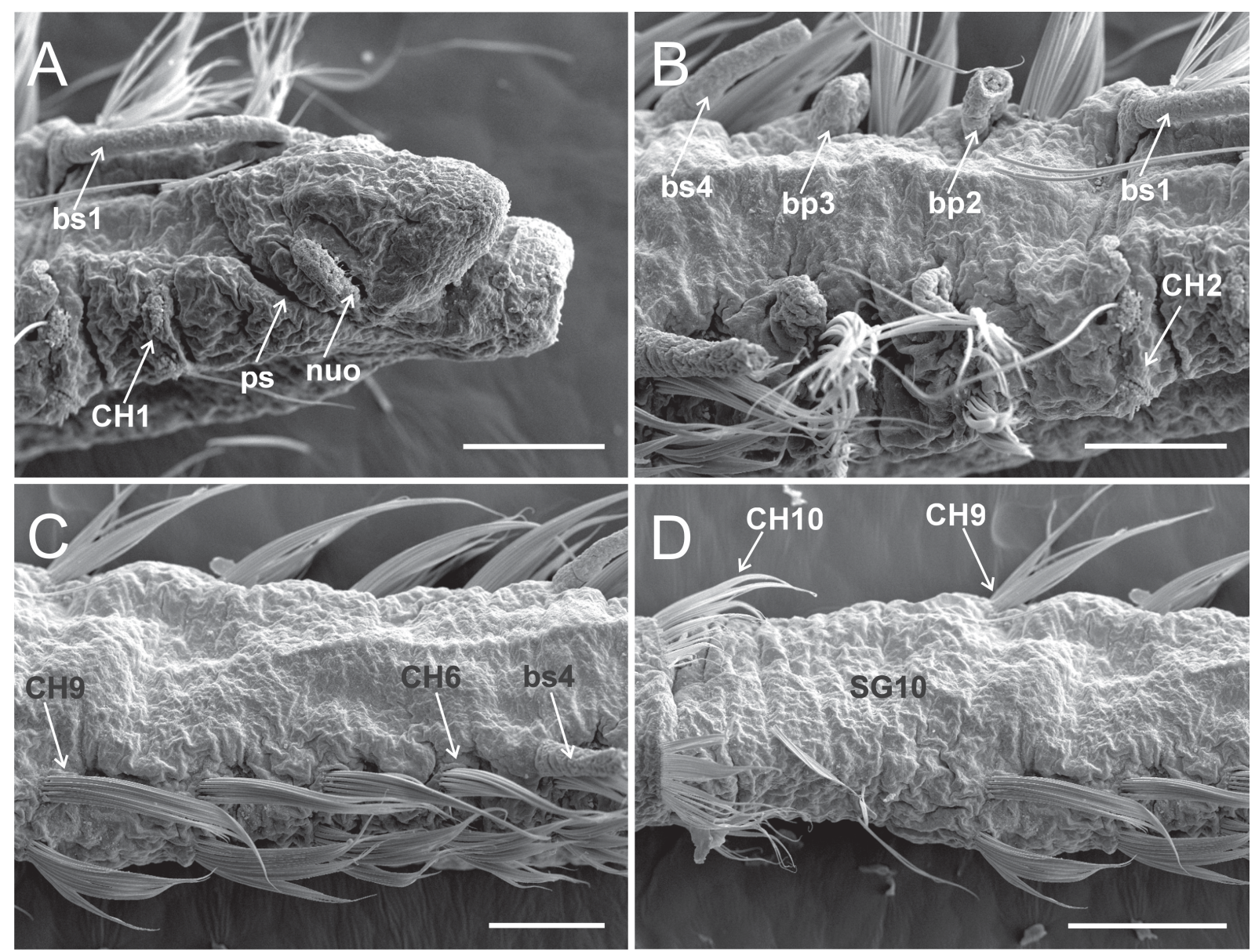

Fig. 4. Heterospio indica sp. nov., paratype (MNCN 16.01/17000), SEM micrographs. A. Anterior end, dorsolateral view $($ scale bar $=100 \mu \mathrm{m})$. B. $\mathrm{CH} 2-\mathrm{CH} 5$, dorsal view $($ scale bar $=100 \mu \mathrm{m})$. C. CH5-CH9, dorsal view $($ scale bar $=100 \mu \mathrm{m})$. D. $\mathrm{CH} 8-\mathrm{CH} 10$, dorsal view $($ scale bar $=15 \mu \mathrm{m})$. Abbreviations: $\mathrm{bp}=$ branchiophore; $\mathrm{bs}=$ branchiostyle; $\mathrm{CH}=$ chaetiger; nuo = nuchal organ; $\mathrm{ps}=$ palp scar; $\mathrm{SG}=$ segment. 

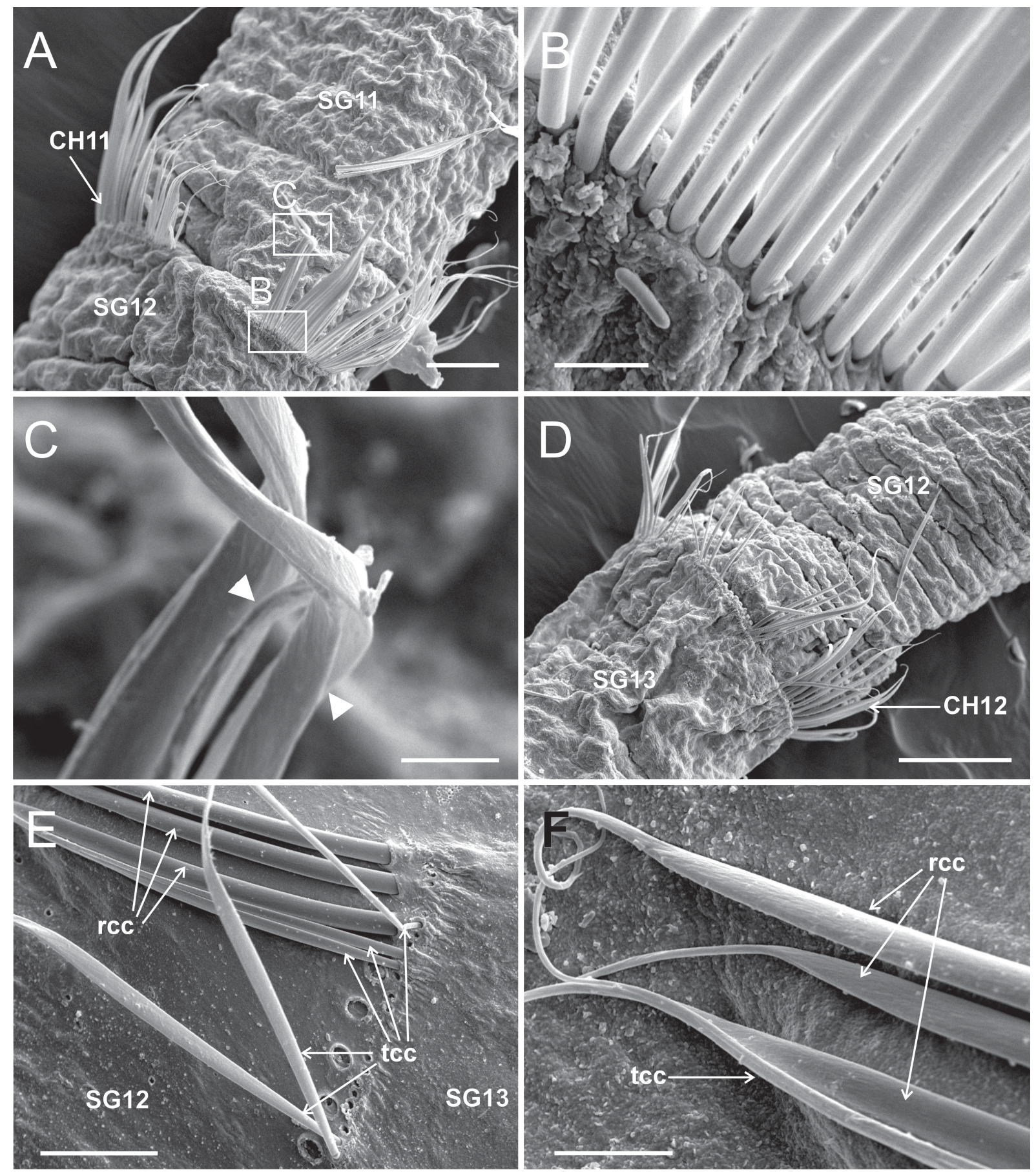

Fig. 5. Heterospio indica sp. nov., paratype (MNCN 16.01/17000), SEM micrographs. A. SG11-SG12, dorsal view, framed areas showing chaetal details in $(B)$ and $(C)($ scale bar $=50 \mu \mathrm{m})$. B. Basal part of CH11 chaetae (scale bar $=5 \mu \mathrm{m}$ ). C. Distal part of CH11 capillary chaetae, arrowheads showing start of distal opening (scale bar $=5 \mu \mathrm{m})$. D. SG12-SG13, dorsal view (scale bar $=100 \mu \mathrm{m})$. E. Basal part of CH12 chaetae (scale bar $=25 \mu \mathrm{m})$. F. Distal part of CH12 chaetae (scale bar $=10 \mu \mathrm{m})$. Abbreviations: $\mathrm{CH}=$ chaetiger; $\mathrm{rcc}=$ robust capillary chaetae; $\mathrm{SG}=$ segment; tcc $=$ thin capillary chaetae . 

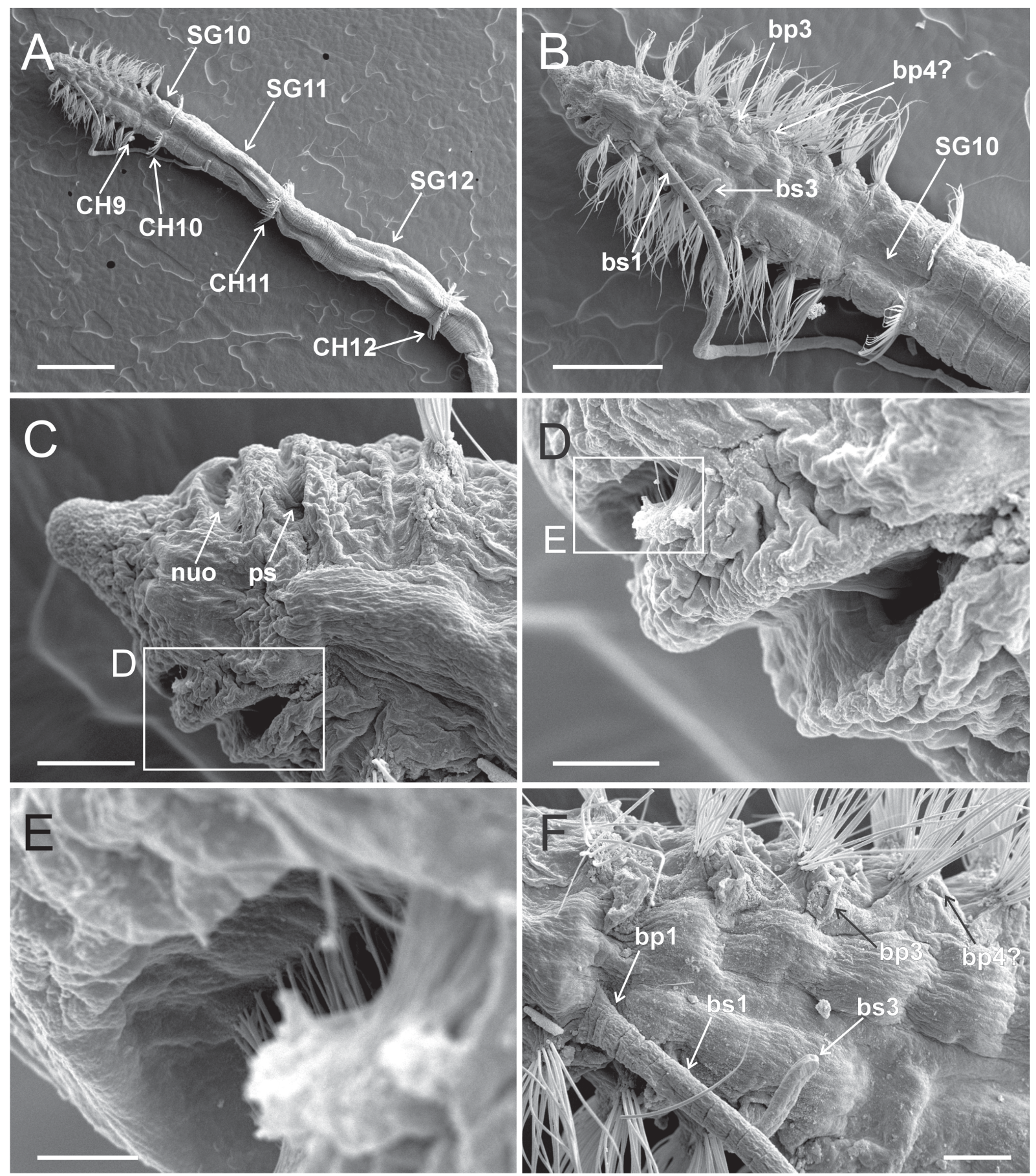

Fig. 6. Heterospio indica sp. nov., paratype (MNCN 16.01/17000), SEM micrographs. A. Anterior end, dorsal view $($ scale bar $=500 \mu \mathrm{m})$. B. Detail of anterior short segments $(\mathrm{SG} 1-\mathrm{SG} 9)$ and first elongated segment $(\mathrm{SG10})($ scale bar $=250 \mu \mathrm{m})$. C. Anterior end, dorsal view, showing nuchal organ and palp scars, framed area shown in (D) (scale bar $=50 \mu \mathrm{m})$. D. Detail of nuchal organ and palp scar, framed area shown in $(\mathrm{E})($ scale bar $=20 \mu \mathrm{m})$. E. Detail of nuchal organ opening $($ scale bar $=5 \mu \mathrm{m})$. F. Detail of branchial area, dorsal view (scale bar $=50 \mu \mathrm{m}$ ). Abbreviations: $b p=$ branchiophore; $b s=$ branchiostyle; $\mathrm{CH}=$ chaetiger; nuo = nuchal organ; $\mathrm{ps}=$ palp scar; $\mathrm{SG}=$ segment. 


\section{Variations}

The first body segments show a certain degree of variation for two relevant taxonomic characters: relative size of first elongated segments and number/size of branchiae. The size of the first elongated segment (CH9) seems constant, about 2.5-3 longer than any short anterior segment (CH1-CH8); the relative size of following elongated segments is somewhat variable: $\mathrm{CH} 10$ is slightly shorter or longer than the anterior body region (i.e., from tip of prostomium to posterior end of CH9). This variability increases for $\mathrm{CH} 11$, which is longer than $\mathrm{CH} 10$ and may be longer than all preceding segments and prostomium together (cf. Fig. 6A vs 8A). Variability in sizes might be dependent on the degree of contraction of the specimen, but it may still be used as a taxonomic character (see Parapar et al. 2014); however, relative sizes of segments should be reviewed across the genus, because this character has not been properly assessed in descriptions of other species. On the contrary, variability in number of branchiae is likely to be size-dependent. Specimens show a wide range of number and sizes of branchiae that seem to be correlated with the size of individuals (i.e., width at level of anterior non-elongated segments; see Fig. 9). The presence and number of branchial pairs increases from anterior to posterior segments; thus, small specimens ( $<0.4 \mathrm{~mm}$ wide) bear four pairs while larger individuals $(0.7-0.95 \mathrm{~mm})$
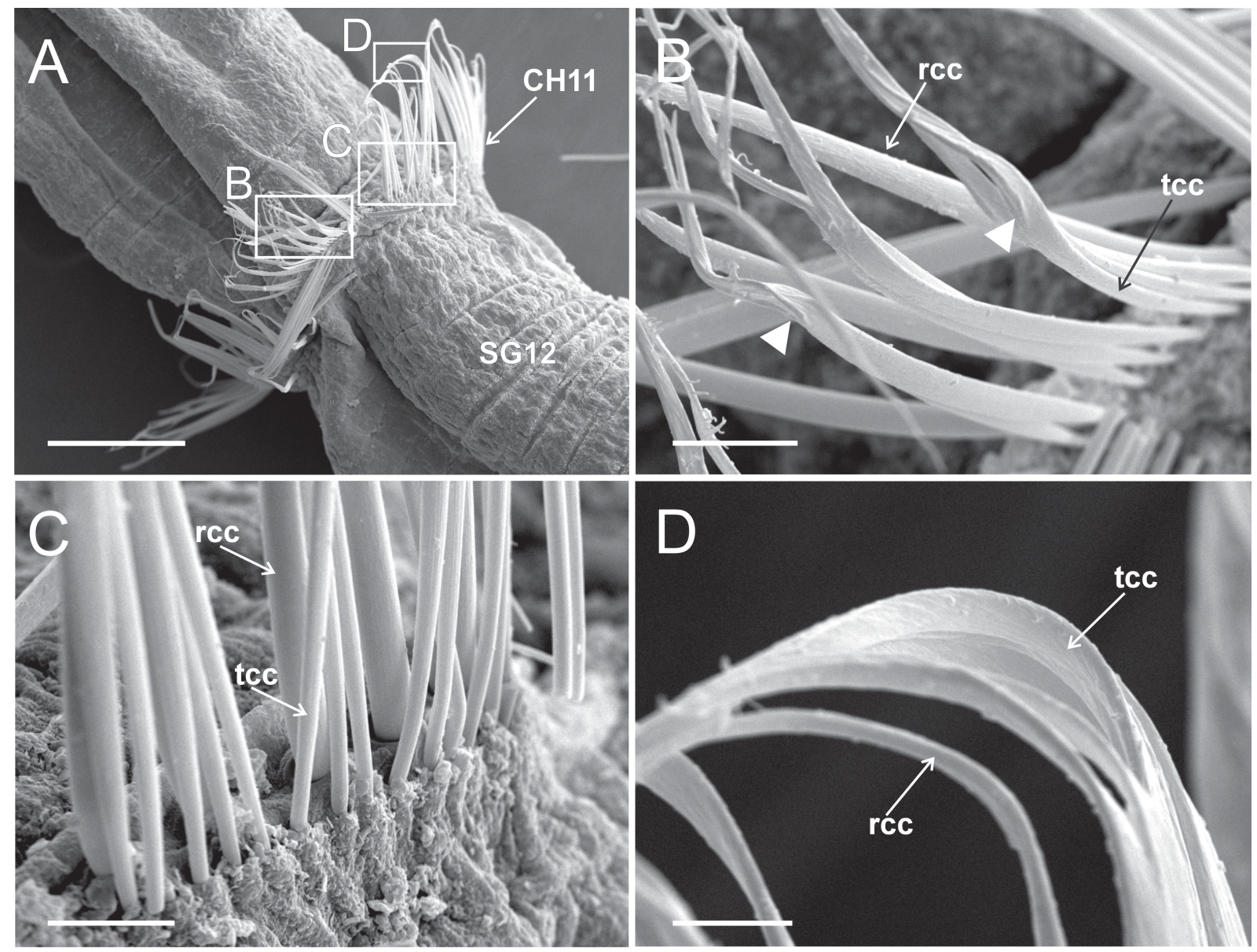

Fig. 7. Heterospio indica sp. nov., paratype (MNCN 16.01/17000), SEM micrographs. A. Elongated SG12, CH11 and flange-like neuropod, framed areas showing chaetal details in (B), (C) and (D) (scale bar $=100 \mu \mathrm{m})$. B. Detail of CH11 chaetae, arrowheads showing start of opening end in thin capillary chaetae (scale bar $=10 \mu \mathrm{m})$. C. Detail of proximal part of both types of CH11 capillary chaetae, anterior body end at left $($ scale bar $=10 \mu \mathrm{m})$. D. Detail of distal part of capillary chaetae $($ scale bar $=5 \mu \mathrm{m})$. Abbreviations: $\mathrm{CH}=$ chaetiger; $\mathrm{rcc}=$ robust capillary chaetae; $\mathrm{SG}=$ segment; $\mathrm{tcc}=$ thin capillary chaetae. 

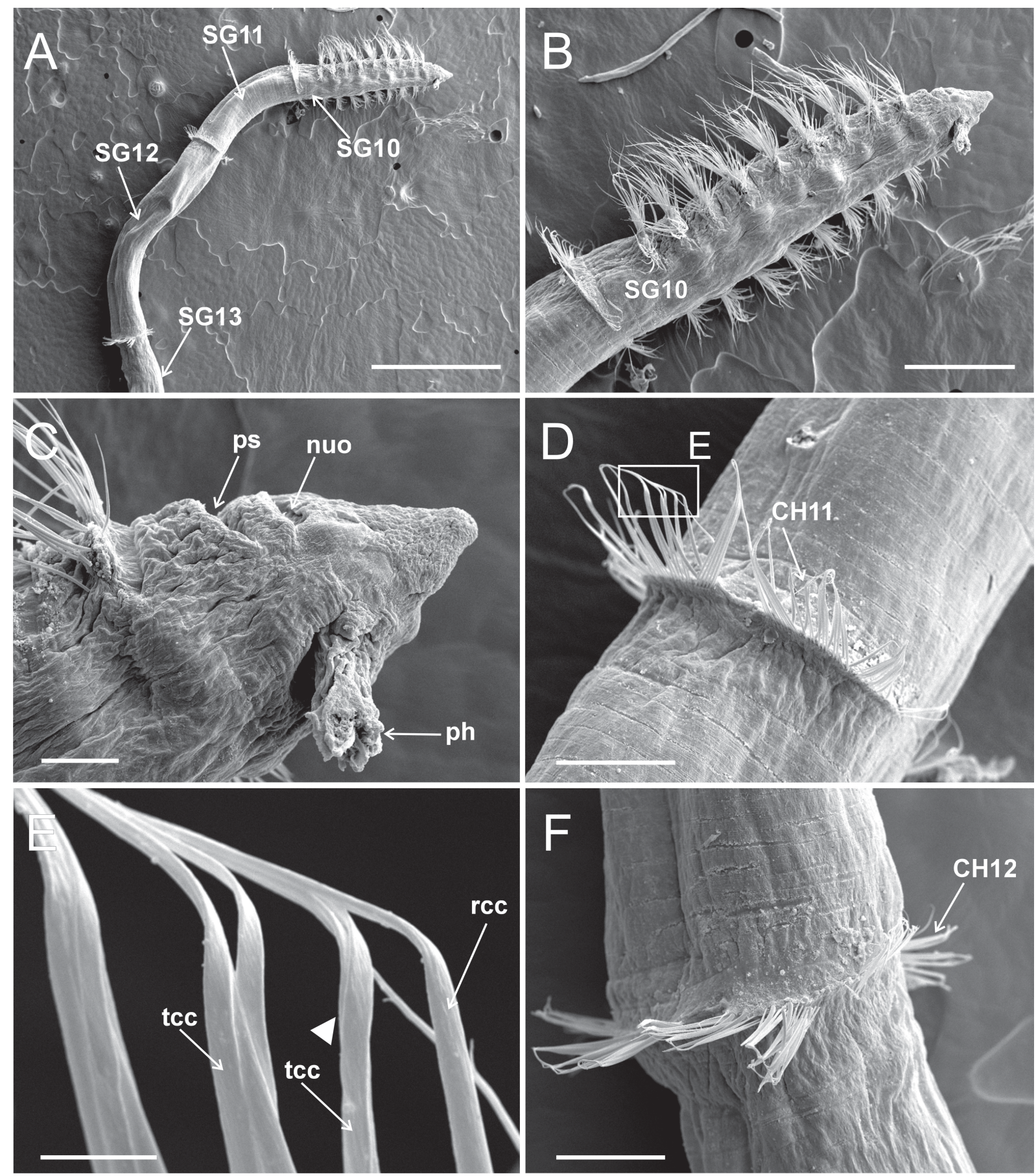

Fig. 8. Heterospio indica sp. nov., paratype (MNCN 16.01/17000), SEM micrographs. A. Specimen showing anterior short segments and first elongated segments, ventro-lateral view (scale bar $=1 \mathrm{~mm}$ ). B. Detail of anterior region, ventro-lateral view (scale bar $=300 \mu \mathrm{m}$ ). C. Detail of anterior end, ventral view (scale bar $=50 \mu \mathrm{m})$. D. Flange-like chaetae of $\mathrm{CH} 11$, framed area showing chaetal detail in (E) $($ scale bar $=100 \mu \mathrm{m})$. E. Detail of distal end of both types of capillary chaetae, arrowheads showing start of opening end in thin capillary chaetae $($ scale bar $=10 \mu \mathrm{m})$. F. Flange-like chaetae of CH12 (scale bar $=$ $100 \mu \mathrm{m})$. Abbreviations: $\mathrm{CH}=$ chaetiger; nuo = nuchal organ; $\mathrm{ph}=$ pharynx; $\mathrm{ps}=$ palp scar; $\mathrm{rcc}=$ robust capillary chaetae; $\mathrm{SG}=$ segment; tcc $=$ thin capillary chaetae. 
show up to 7-8 pairs. The presence and size of branchiophores and branchiostyles also shows certain variability, e.g., in the same specimen there are large and thin branchiostyles indistinctly on large and small branchiophores.

All specimens are broken at the level of the anterior elongated segments (CH12 to $\mathrm{CH} 15)$ but a posterior region could be examined from a posterior end found in a Malvan sample in March 2015. Only one posterior region was found, composed of 7 elongated segments and a bulb-like inflated posterior end provided with 5 chaetigers, a terminal achaetigerous segment and pygidium (Fig. 3A). The last 5 chaetigers are provided with 2-4 acicular hooks (Fig. 3B); the anteriormost elongated chaetiger bears chaetae similar to those of $\mathrm{CH} 10$ of the holotype, with flattened distal ends; the chaetae of the other four elongated chaetigers are similar to those of $\mathrm{CH} 12-14$ of the holotype, i.e., of capillary and subuluncini type.

\section{Specimen from Sudan}

The specimen collected by Rosenfeldt (1989) off the coast of Sudan, which was identified as H. longissima (SMF 3795), has also been examined. It is in poor condition, i.e., incomplete, broken in two pieces,

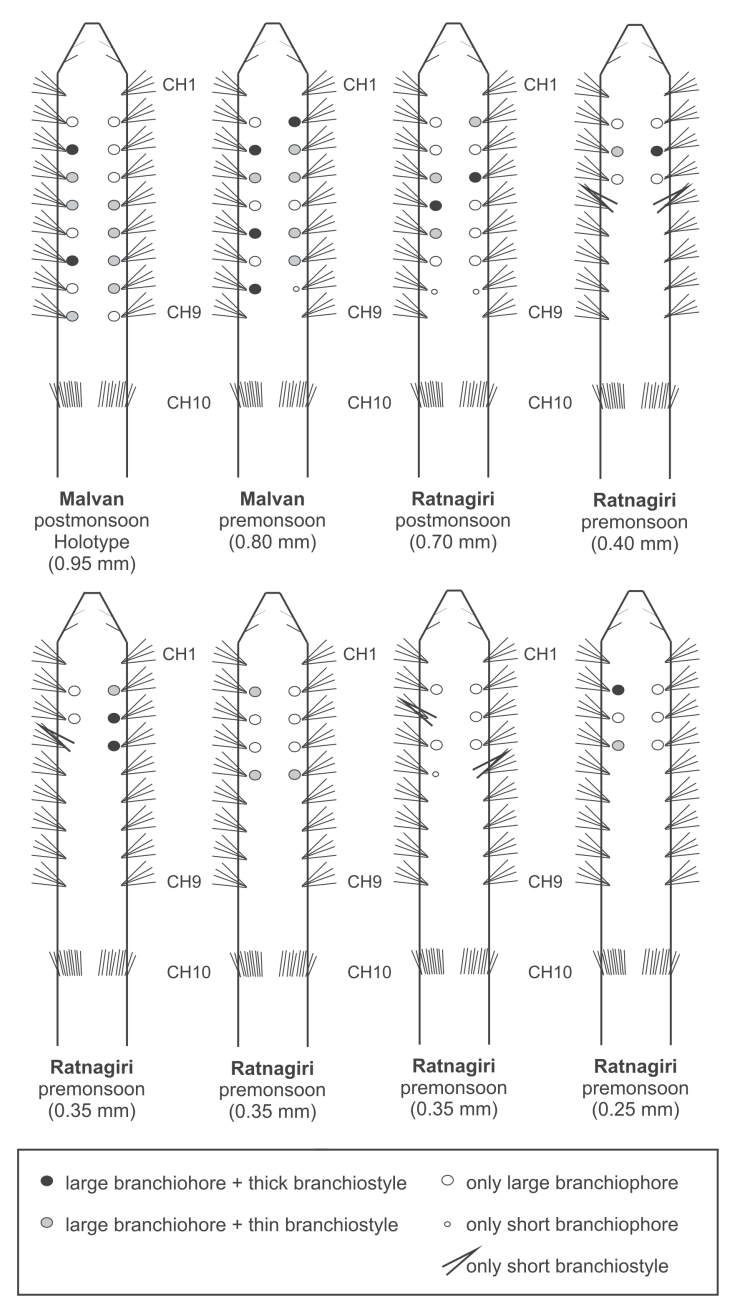

Fig. 9. Schematic drawings (not to scale) in dorsal view of some paratypes (MNCN and NIO) of Heterospio indica sp. nov., showing diversity of branchial arrangement in relation to size. Chaetigers numbered from $\mathrm{CH} 1$ (biramous) to $\mathrm{CH} 10$ (first flange-like). Width of anterior region indicated. 
twisted and flattened dorsoventrally. According to its width $(0.6 \mathrm{~mm})$, this specimen fits within the range of large $H$. indica sp. nov. and it bears eight pairs of branchiae. Rosenfeldt (1989) highlighted the presence of palps which are now lacking. However, the relevant features of this specimen agree well with the description provided above of $H$. indica sp. nov.

\section{Distribution and ecology}

Heterospio indica sp. nov. was found off the west coast of India (Fig. 1) in shallow water (2.5 to $22 \mathrm{~m}$ depth) in mostly clayey silt and sandy silt sediments (Table 1). Hartman (1974) reported H. longissima based on two specimens from off the NW coast of India and Pakistan. In this article, Hartman (1974) only mentioned the papers by Ehlers (1895) and Hartman (1965) and did not provide any comparison with $H$. mediterranea or $H$. reducta, the two species described earlier by Laubier et al. (1972-73) from the Mediterranean Sea. Rosenfeldt (1989) reported H. longissima from Sudan (see above) based on a single specimen. She illustrated chaetae of the second elongated segment but did not provide any comparison with other species of Heterospio. Türkay (1996), Wehe \& Fiege (2002), Rao (2005) and Kazmi \& Naushaba (2013) mentioned these two records without any discussion of the identification of the reported material. We did not examine the material reported by Hartman (1974) but assume that it may belong to $H$. indica sp. nov. because of its geographic proximity to our material. The finding of the specimen originally reported as H. longissima by Rosenfeldt (1989) and identified here as $H$. indica sp. nov. (see above) extends the distribution of the new species to the Red Sea.

\section{Key to world species of Heterospio}

The key presented below is based on the provided by Bochert \& Zettler (2009) but here the position and relative length of the first elongated chaetiger (FECH) and the number of pairs of branchiae have prevalence over chaetal types. The position of FECH in the species follows Parapar et al. (2014).

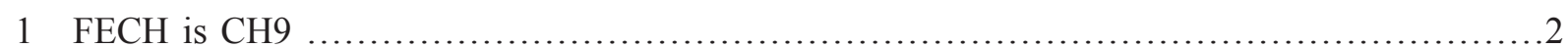

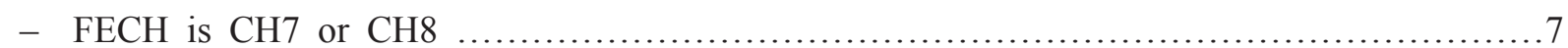

2. Acicular chaetae in neuropodium of $\mathrm{CH} 1$........................... catalinensis Hartman, 1944

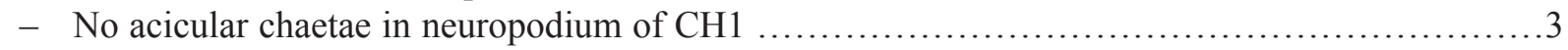

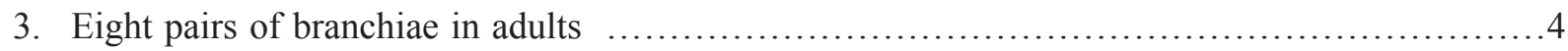

- Four pairs of branchiae in adults................................... peruana Borowski, 1994

4. FECH of almost same length as all anterior chaetigers together ......H. longissima Ehlers, 1874

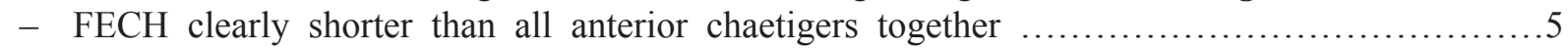

5. Capillary chaetae of elongated segments (ES) with flattened distal end ........H. indica sp. nov.

- Capillary chaetae of ES not flattened ........................................................

6. Aristate chaetae present on elongated chaetigers .................H. sinica Wu \& Chen, 1996

- Aristate chaetae absent on elongated chaetigers ..............H. longissima sensu Hartman 1965

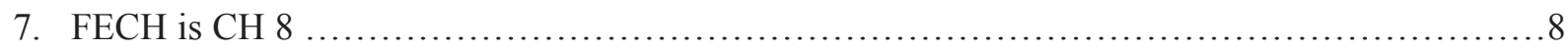

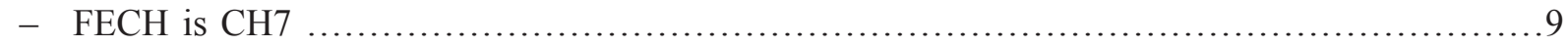

8. Five (or six) pairs of branchiae ..........................Heterospio sp. A sensu Uebelacker 1984

- Seven pairs of branchiae .......................H. mediterranea Laubier, Picard \& Ramos, 1973

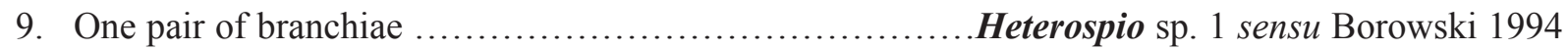

- Three pairs of branchiae ............................................................... 
10. Length of $\mathrm{CH} 8$ about $1 / 2$ that of all anterior chaetigers together; very long chaetae in $\mathrm{CH} 8$

H. reducta Laubier, Picard \& Ramos, 1973

- Length of $\mathrm{CH} 8$ about $1 / 3$ that of all anterior chaetigers together; chaetae in $\mathrm{CH} 8$ similar to preceeding H. angolana Bochert \& Zettler, 2009

\section{Remarks}

According to the relative size of anterior segments, Heterospio indica sp. nov. most closely resembles H. longissima (both the nominal species and H. longissima sensu Hartman 1965), H. catalinensis, $H$. peruana and $H$. sinica. In these species, the first elongated chaetiger is $\mathrm{CH} 9$ while in $H$. mediterranea, H. reducta, H. angolana, Heterospio sp. A sensu Uebelacker 1984 and Heterospio sp. 1 sensu Borowski 1994, it corresponds to either CH7 or CH8 (see figs 5 and 6 in Parapar et al. 2014). In Heterospio indica sp. nov., H. longissima sensu Hartman 1965, H. peruana and H. sinica, CH9 is about three times longer than any anterior segment $(\mathrm{CH} 1-\mathrm{CH} 8)$. By contrast, $\mathrm{CH} 9$ is about as long as all anterior segments altogether in $\mathrm{H}$. longissima Ehlers, 1874 ; H. catalinensis has a CH9 which is slightly longer than $\mathrm{CH} 1-$ $\mathrm{CH} 8$ and bears acicular chaetae in the neuropodium of $\mathrm{CH} 1$. Heterospio peruana only bears four pairs of branchiae while H. indica sp. nov., H. longissima sensu Hartman 1965 and H. sinica bear eight pairs instead.

The flattened distal end of the capillary chaetae in the elongated segments in $H$. indica sp. nov. clearly distinguishes the new species from H. longissima sensu Hartman 1965 and H. sinica; in the former, both type of capillary chaetae are greatly different in size and shape while $H$. sinica bears aristate chaetae which are not found in the new species.

The COI and 18S SSU rDNA sequences from $H$. indica sp. nov. are publically available on GenBank and can be used as a reference for future molecular taxonomic and phylogenetic studies. They are the first DNA sequences published for any species of Longosomatidae.

\section{Discussion}

The main taxonomic characters of the genus Heterospio are the number and length of anterior elongated segments, the presence or absence of palps and/or nuchal organs, the number of pairs of branchiae, and chaetal morphology (see Parapar et al. 2014). The study of specimens of $H$. indica sp. nov., however, allowed us to amend some comments given by Parapar et al. (2014). For instance, the presence of palps in Heterospio has been described and/or illustrated in several previous works (e.g., Hartman 1965; Wu \& Chen 1966; Laubier et al. 1973; Borowski 1994); other authors, however, questioned their very presence (Uebelacker 1984; Bochert \& Zettler 2009; Parapar et al. 2014) by interpreting the deep grooves behind the prostomium as nuchal organs and therefore not as palp scars. Examination of specimens of $H$. indica sp. nov. has clearly demonstrated that both palps and nuchal organs are indeed present.

As was previously proposed by Parapar et al. (2014), we consider that the number of short anterior segments and the relative length of the first elongated segments are two key characters in longosomatid taxonomy; nevertheless, they should be evaluated carefully because some variation was observed (see above).

Chaetal terminology in Longosomatidae is surprisingly variable given the small number of described species. The following terminology has been used for chaetae: aristate, capillary, stout capillary, subuluncini, transitional subuluncini capillary-like, spines and acicular hooks. A review of this nomenclature, in the frame of an eventual revision of the genus, seems necessary since some types might simply be transitional stages of the same type of chaetae, as has already been discussed by Borowski (1994). 


\section{Acknowledgements}

The authors are grateful to Ada Castro (SAIN, UDC) for assisting in the preparation of specimens and use of the SEM, and Dieter Fiege (Senckenberg Research Institute and Natural History Museum, Frankfurt) who kindly provided the specimen collected by Pongchai Rosenfeldt in the Red Sea. JP and JM thank the Fauna Ibérica Project (Polychaeta VI: Palpata-Canalipalpata I; CGL2014-53332-C5-3-P) for partial financial support. TV and SS thank MoES (Ministry of Earth Sciences) for providing financial support through the COMAPS (Coastal Ocean Monitoring and Prediction System) programme and also the Director of CSIR-National Institute of Oceanography for extending facilities. This is CSIR-NIO contribution no. 5875. We thank Pat Hutchings (Australian Museum, Sydney) for checking the English language. Two anonymous referees provided useful comments that greatly contributed to improve this paper. TV is grateful to CSIR for awarding a Senior Research Fellowship that gave her the opportunity to carry out the present study.

\section{References}

Bochert R. \& Zettler M.L. 2009. A new species of Heterospio (Polychaeta, Longosomatidae) from offshore Angola. Zoological Science 26 (10): 735-737. http://dx.doi.org/10.2108/zsj.26.735

Borowski C. 1994. New records of Longosomatidae (Heterospionidae) (Annelida, Polychaeta) from the abyssal Southeast Pacific, with the description of Heterospio peruana sp. nov. and a general remark on the family. Mitteilungen aus dem Hamburgischen Zoologischen Museum und Institut 92 (Suppl. 1): $129-144$.

Ehlers E. 1874. Annulata nova vel minus cognita in Expeditione "Porcupine" capta. The Annals and Magazine of Natural history, Ser. 4. 13: 292-298. Available from http://biodiversitylibrary.org/ page/24342680 [accessed 6 Jul. 2016]

Folmer O., Black M., Hoeh W., Lutz R. \& Vrijenhoek R. 1994. DNA primers for amplification of mithochondrial cytochrome c oxidase subunit I from diverse metazoan invertebrates. Molecular Marine Biology and Biotechnology 3: 294-299.

Hartman O. 1965. Deep-water benthic polychaetous annelids off New England to Bermuda and other North Atlantic areas. Allan Hancock Foundation, Occasional Papers 28: 1-378.

Hartman O. 1974. Polychaetous annelids of the Indian Ocean including an account of species collected by members of the international Indian Ocean Expeditions, 1963-'64 and a catalogue and bibliography of the species from India. Journal of the Marine Biological Association of India 16: 191-252.

Kazmi Q.B. \& Naushaba R. 2013. Checklist of marine worms reported from Pakistani marine waters. Pakistan Journal of Nematology 31: 187-280.

Knox G.A. 1960. The polychaete family Longosomatidae in New Zealand. Nature 187: 1131.

Laubier L., Picard C. \& Ramos J. 1973. Les Heterospionidae (Annélides polychaetes sédentaires) de Méditerranée Occidentale. Vie et Milieu 23: 243-254.

Medlin L., Elwood H.J., Stickel S. \& Sogin M.L. 1988. The characterization of enzymatically amplified eukaryotic 16S-like rRNA-coding regions. Gene 71: 491-499. http://dx.doi.org/10.1016/0378$\underline{1119(88) 90066-2}$

Norlinder E., Nygren A., Wiklund H. \& Pleijel F. 2012. Phylogeny of scale-worms (Aphroditiformia, Annelida), assessed from 18SrRNA, 28SrRNA, 16SrRNA, mitochondrial cytochrome c oxidase subunit I (COI), and morphology. Molecular Phylogenetics and Evolution 65: 490-500. http://dx.doi. org/10.1016/j.ympev.2012.07.002 
Parapar J., Aguirrezabalaga F. \& Moreira J. 2014. First record of Longosomatidae (Annelida: Polychaeta) from Iceland with a worldwide review of diagnostic characters of the family. Journal of Natural History 48: 983-998. http://dx.doi.org/10.1080/00222933.2013.859316

Rao D.V.S. 2005. Comprehensive review of the records of the biota of the Indian Seas and introduction of non-indigenous species. Aquatic Conservation 15 (2): 117-146. http://dx.doi.org/10.1002/aqc.659

Rosenfeldt P. 1989. Die Polychaeta der Rotmeer-Expeditionen MESEDA I (1977) mit FS "SONNE" und MESEDA II (1979) mit FS "VALDIVIA“. Senckenbergiana Biologica 69: 213-242.

Rouse G. 2001. Heterospio Ehlers, 1875. In: Rouse G.W. \& Pleijel F. (eds) Polychaetes: 264-265. Oxford University Press, Oxford.

Türkay M. 1996. Composition of the deep Red Sea macro- and megabenthic invertebrate fauna. Zoogeographic and ecological implications. In: Uiblein F., Ott J. \& Starhowitsch M. (eds) Deep-sea and Extreme Shallow-water Habitats: Affinities and Adaptations. Biosystematics and Ecology Series 11: 43-59.

Uebelacker J.M. 1984. Family Heterospionidae Hartman, 1963. In: Uebelacker J.M., Johnson P.G., Vittor B.A. \& Associates (eds) Taxonomic Guide to the Polychaetes of the Northern Gulf of Mexico, Vol. II: 1-6. U.S. Department of the Interior, Minerals Management Service, Metairie, Alabama, USA.

Wehe T. \& Fiege D. 2002. Annotated Checklist of the Polychaete Species of the Seas Surrounding the Arabian Peninsula: Red Sea, Gulf of Aden, Arabian Sea, Gulf of Oman, Arabian Gulf. Fauna of Arabia 19, Riyadh, Saudi Arabia.

Wilson R.S. 2000. Family Longosomatidae. In: Beesley P.L., Ross G.J.B. \& Glasby C.J. (eds) Polychaetes and Allies: the Southern Synthesis: 193. CSIRO Publishing, Melbourne.

Wu B.L. \& Chen M. 1966. A new and interesting species of the genus Heterospio (Polychaeta, Heterospionidae). Oceanology and Limnology Sinica 8: 163-167.

Manuscript received: 27 August 2015

Manuscript accepted: 21 March 2016

Published on: 9 August 2016

Topic editor: Rudy Jocqué

Desk editor: Kristiaan Hoedemakers

Printed versions of all papers are also deposited in the libraries of the institutes that are members of the EJT consortium: Muséum national d'Histoire naturelle, Paris, France; Botanic Garden Meise, Belgium; Royal Museum for Central Africa, Tervuren, Belgium; Natural History Museum, London, United Kingdom; Royal Belgian Institute of Natural Sciences, Brussels, Belgium; Natural History Museum of Denmark, Copenhagen, Denmark; Naturalis Biodiversity Center, Leiden, the Netherlands. 